\title{
Smartphone addiction is increasing across the world: A meta-analysis of 24 countries $^{*}$
}

\author{
Jay A. Olson Dasha A. Sandra Élissa S. Colucci \\ Alain Al Bikaii Denis Chmoulevitch Johnny Nahas \\ Amir Raz Samuel P. L. Veissière
}

\begin{abstract}
Smartphone ownership and screen time are increasing across the world, but there have been few attempts to quantify smartphone addiction on a global scale. We conducted a meta-analysis of studies published between 2014 and 2020 that used the Smartphone Addiction Scale, the most common measure of problematic smartphone use. We focused on adolescents and young adults (aged 15 to 35) since they tend to have the highest screen time and smartphone ownership rates. Across 24 countries, 83 samples, and 33,831 participants, we demonstrate that problematic smartphone use is increasing across the world. China, Saudi Arabia, and Malaysia had the highest scores while Germany and France had the lowest. We suggest that the clinical interpretation of these scores should be updated given current global trends.
\end{abstract}

\section{Introduction}

Smartphone ownership has increased over the past decade, reaching around half or more of the global population (Newzoo, 2021; O'Dea, 2021). In high-income countries across North America and Europe, over $80 \%$ of the population owns a smartphone, and rates in low- and middle-income countries continue to rise (Newzoo, 2018, 2019). While several organisations track objective measures such as smartphone ownership and screen time patterns (GlobalWebIndex, 2018; Newzoo, 2021; O’Dea, 2021; Pew Research Center, 2019;

*Preprint of manuscript accepted in Computers in Human Behavior. Corresponding author: J. A. Olson (jay.olson@mail.mcgill.ca). 
Rideout \& Robb, 2019), few have attempted to quantify the more subjective aspects of smartphone use across the world.

For example, problematic smartphone use occurs when smartphones interfere with daily life (Busch \& McCarthy, 2021; Panova \& Carbonell, 2018). It generally correlates with screen time (e.g., Randjelovic et al., 2020) but is a distinct construct; high screen time alone does not necessarily cause negative effects. For example, some people may benefit from calling their friends for several hours per day, while others who use social networking apps for only a few minutes while trying to study or sleep may experience negative effects (Sohn et al., 2021). Problematic smartphone use has been associated with cognitive impairments (Wilmer et al., 2017), lower sleep quality (Demirci et al., 2015), and depression (Elhai et al., 2017; Geng et al., 2021); limiting smartphone use can reduce depression and improve sleep quality (Hughes \& Burke, 2018; Hunt et al., 2018; Olson et al., 2021). However, researchers continue to debate about the precise relationship between smartphone use and various aspects of well-being (Davidson et al., 2020; Przybylski, 2019; Twenge et al., 2020) as well as whether problematic smartphone use constitutes a behavioural addiction (Kardefelt-Winther et al., 2017; Panova \& Carbonell, 2018; Satchell et al., 2020). In any case, many people report wanting to reduce their smartphone use (Olson et al., 2021). Almost half of smartphone users in developed countries believe they are over-using their phones (Deloitte, 2019) and many would rather spend their time doing something else (Deloitte, 2018; Lukoff et al., 2018), yet only half of those trying to reduce their phone use report successfully doing so (Deloitte, 2018).

One of the challenges with quantifying problematic smartphone use across the world is the plethora of measures available (Abendroth et al., 2020; Davidson et al., 2020). There are at least 78 different scales (Harris, Regan, et al., 2020), many of which correlate well with each other (Davidson et al., 2020; Harris, McCredie, et al., 2020), assessing similar constructs relevant to behavioural addictions (Sohn et al., 2019). However, these measures 
vary in their criteria for what constitutes problematic behaviour or risk of addiction (Abendroth et al., 2020; Davidson et al., 2020; Gutiérrez et al., 2016), making it difficult to directly compare scores across studies.

The most-cited measure of problematic smartphone use is the Smartphone Addiction Scale (SAS; Kwon, Lee, et al., 2013) along with its short version (SAS-SV; Kwon, Kim, et al., 2013). As of November 2021, these two measures have over 2,200 combined citations on Google Scholar. The measures were developed in collaboration with clinicians and capture a variety of components related to behavioural addictions: withdrawal, tolerance, loss of control, intense desire to use, neglect of other activities, and continued use despite harm (Sohn et al., 2019). Both measures use items such as: "I have a hard time concentrating in class, while doing assignments, or while working, due to smartphone use" $^{\prime \prime}$ Participants rate their agreement on six-point Likert scales; higher total scores indicate more problematic smartphone use. The full version of the scale captures more shared variance than several other related measures (Davidson et al., 2020) and the short version predicts clinical judgements of smartphone addiction (Kwon, Kim, et al., 2013).

Here, we present a global meta-analysis of these measures. We hypothesised that country, age, and gender, and year would predict problematic smartphone use. To our knowledge, this is the largest meta-analysis of global problematic smartphone use using comparable measures.

\section{Methods}

\subsection{Search strategy}

We used Google Scholar to collect the articles, since it returns the most entries compared to other databases (e.g., Wright et al., 2014). Using the "Cited by" function, we collected all of the articles citing either of the two original SAS papers (Kwon, Lee, et al., 2013; 
Kwon, Kim, et al., 2013) until July 2020. Figure 1 shows a PRISMA flow chart of the process (Moher et al., 2009).

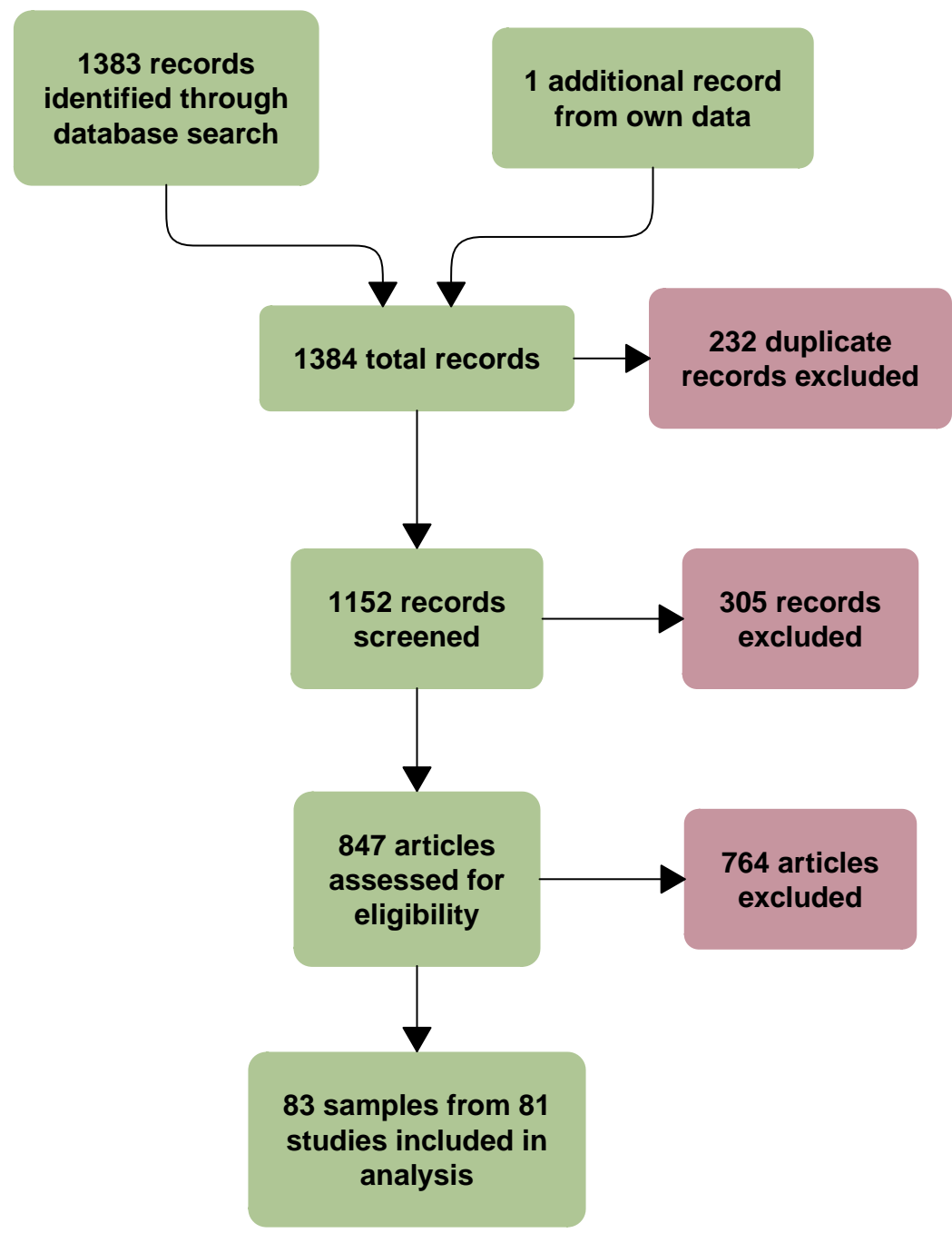

Figure 1: PRISMA flow chart of study inclusion and exclusion.

\subsection{Eligibility criteria}

We first removed duplicates based on the article title using the metagear $\mathrm{R}$ package (Lajeunesse, 2015). We then kept articles published in English with the full text available anywhere (e.g., via institutional access, Google Scholar, or Library Genesis); we were able to access all potentially eligible records. After this initial screening, we ensured that each 
entry:

- was published in a peer-reviewed journal (based on Ulrich's Periodicals Directory or by checking the journal's website),

- studied smartphones (not tablets),

- presented original research (e.g., not a review or re-analysis of existing data),

- recruited a non-clinical population (e.g., not patients),

- had a sample size of at least 20,

- reported the average age or age range of the sample between 15 and 35 (inclusive), since adolescents and young adults tend to have the highest screen time and smartphone ownership rates,

- reported the overall SAS or SAS-SV average or enough information to compute it (e.g., individual item scores).

\subsection{Coding procedure}

From each article, raters then extracted:

- the publication year,

- the country of the sample,

- the age mean, standard deviation, and range (or, if the average was omitted, we estimated it based on the midpoint of the range),

- the percent of female participants, ${ }^{1}$

- the sample size,

\footnotetext{
${ }^{1}$ Two studies with otherwise eligible all-male samples (Dey et al., 2019; Enwereuzor et al., 2016) (and thus extreme scores on the percent of female participants) were excluded to meet statistical assumptions and to keep the studies comparable.
} 
- whether there were relevant subsamples (such as two samples from different countries),

- which questionnaire version was used, and

- the SAS or SAS-SV mean, standard deviation, and range.

During the first pass, two raters assessed eligibility and extracted the data before a third rater resolved discrepancies. During the second pass, another rater assessed eligibility and re-extracted the data, agreeing with $97 \%$ of the eligibility ratings from the first pass. A final rater resolved the remaining discrepancies.

\subsection{Analysis}

To ease comparison between the two measures, we translated the 33-item SAS scores into 10-item SAS-SV scores. We used data from Harris and colleagues (2020) who found a strong linear relationship between the measures $(r=.94, N=150$; Figure A1). Using their raw data (https://osf.io/tq3wv/), we translated the SAS scores to estimated SAS-SV scores which are the focus of our analysis:

$$
\widehat{\mathrm{SAS}_{\mathrm{SV}}}=.3191 \times \mathrm{SAS}-2.3677
$$

To assess variation in problematic smartphone use, we conducted an ANOVA testing for main effects of publication year, country, age, and gender (i.e., percent of female participants). We used the sample sizes as unit weights in the regression (Hunter \& Schmidt, 2004); we could not use variance-based weights since some manuscripts omitted measures of variability. All $\alpha$ values were .05 with no family-wise error correction. 


\section{Results}

\subsection{Descriptive statistics}

In total, we included 83 samples from 81 studies. The median number of participants was $316(M=408, S D=348$, range: 40 to 1889$)$ and most were women $(60 \%)$. The average age of each sample was between 16 and 32. In total, these samples captured 33,831 participants from 24 countries.

The full SAS ranges from 48 to 288 , with higher scores indicating more problematic smartphone use. The 30 samples using the SAS showed an average score of 89.96 (SD = 12.93). The SAS-SV ranges from 10 to 60 , and the 53 samples using it showed an average of $30.16(S D=3.53)$. Combining the scales by translating the SAS to the SAS-SV, we saw an overall average of $28.78(S D=4.16)$, which is equivalent to weakly disagreeing with each scale item (scoring around 3 out of 6 ).

\subsection{Publication year}

Problematic smartphone use increased over time. Figure 2 shows the pooled means increasing by year across most of the countries (unweighted $r(81)=.39[.19, .56]$ ), which accounted for $11 \%$ of the variation in the model (Table 1 ).

Table 1: ANOVA results. Problematic smartphone use (estimated SAS-SV) varied by publication year and country.

\begin{tabular}{lrrrrr}
\hline Factor & $d f$ & $S S$ & $F$ & $p$ & $\eta^{2}$ \\
\hline Publication year & $\mathbf{1}$ & $\mathbf{6 7 6 3 0 . 3 3}$ & $\mathbf{4 0 . 0 8}$ & $<\mathbf{0 . 0 0 1}$ & $\mathbf{. 1 1 2}$ \\
Country & $\mathbf{2 1}$ & $\mathbf{4 4 9 5 5 3 . 2 6}$ & $\mathbf{1 2 . 6 9}$ & $<\mathbf{0 . 0 0 1}$ & $\mathbf{. 7 4 2}$ \\
Average age & 1 & 1022.25 & 0.61 & 0.440 & .002 \\
Percent female & 1 & 287.51 & 0.17 & 0.681 & .000
\end{tabular}




\begin{tabular}{lrrrrr}
\hline Factor & $d f$ & $S S$ & $F$ & $p$ & $\eta^{2}$ \\
\hline Residuals & 52 & 87753.60 & & & .145 \\
\hline
\end{tabular}

\subsection{Country}

Problematic smartphone use varied considerably by country (Figure 3), accounting for $74 \%$ of the total variation. The highest consistent scores were seen in China and Saudi Arabia, followed by Malaysia, Brazil, South Korea, Iran, Canada, and Turkey. Most of these are collectivist countries which emphasise social hierarchy and conformity (Minkov, 2018). They also show cultural tightness with relatively pervasive and closely followed social norms (Uz, 2015). Compared to more culturally loose countries, the more formal social and family obligations may provide a cultural incentive to stay in contact through smartphones more frequently. Indeed, the social uses of phones best predict problematic use (Lopez-Fernandez et al., 2017; van Deursen et al., 2015; Veissière \& Stendel, 2018). One study also found a link between collectivism and nomophobia, the anxiety due to lacking one's phone (Arpaci, 2017). In contrast, the individualistic and culturally loose countries of Germany and France showed the lowest problematic smartphone use. In an exploratory test, we saw a negative correlation between cultural looseness and problematic use by country (unweighted $r(15)=-.56[-.82,-.10]$; Figure $4 \mathrm{~A}$ ).

In addition to cultural looseness, we explored two other country-level measures. Problematic smartphone use seemed to show non-linear relationships with both country-wide smartphone ownership (Figure 4B) and smartphone internet screen time (Figure 4C). Future meta-analyses with more countries are needed to confirm and explain these potential non-linear relationships. 


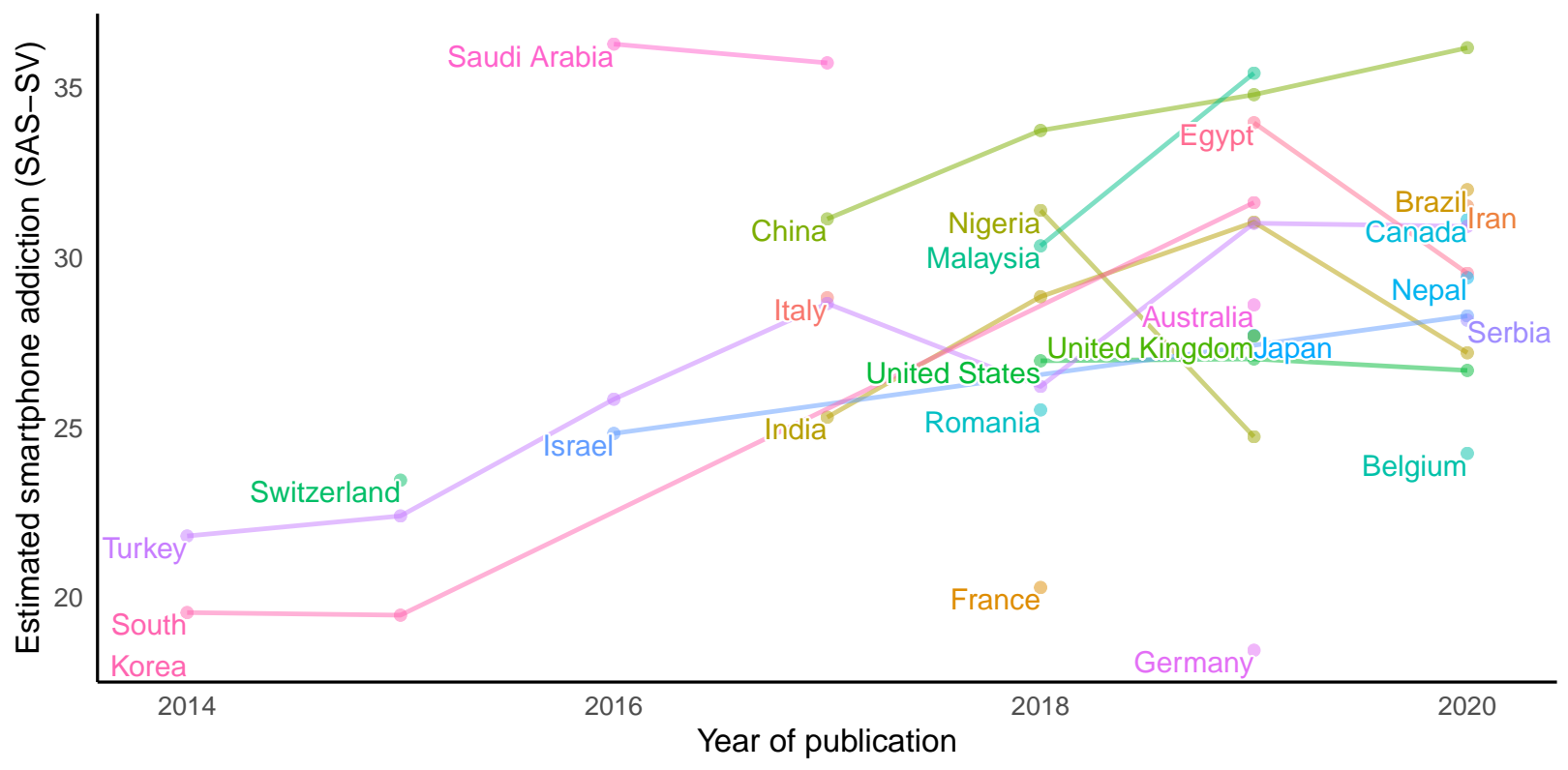

Figure 2: Problematic smartphone use increased over time in most countries. Dots show pooled means and lines show change over time. The total score can range from 10 to 60.

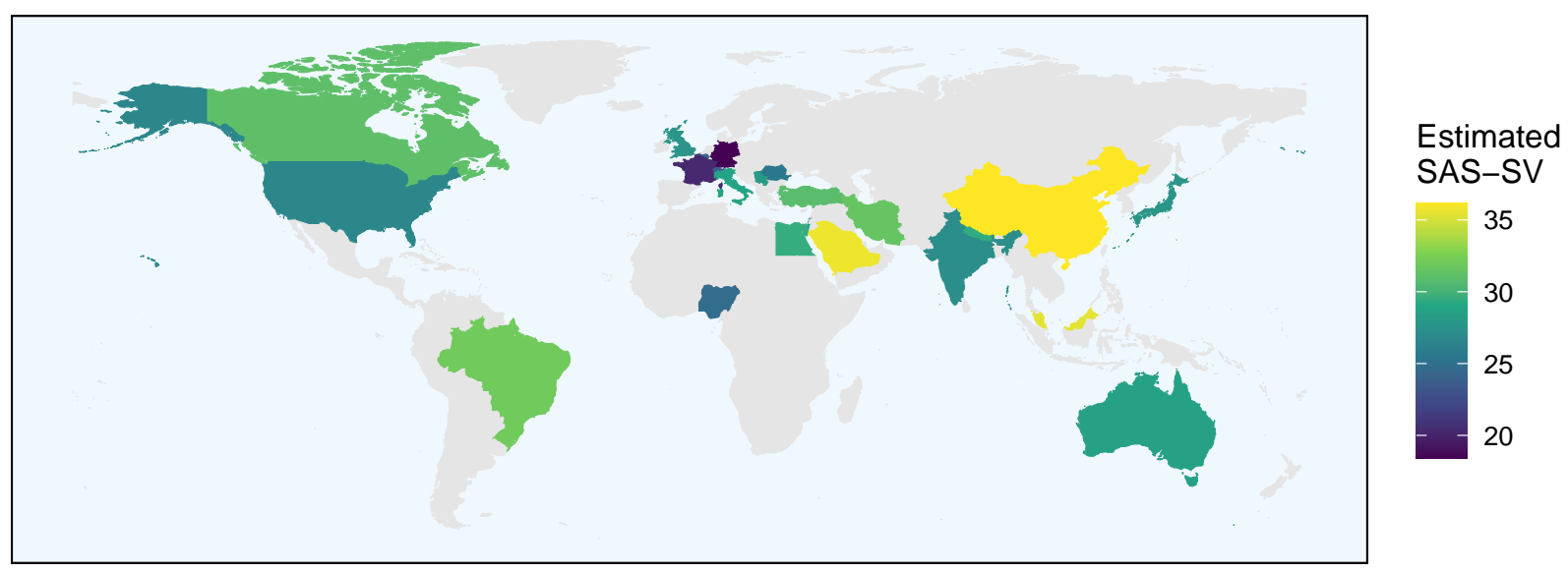

Figure 3: Most recent eligible problematic smartphone use scores by country. SAS scores were translated into estimated SAS-SV scores for a consistent scale; see Figure A2 for maps of each measure. 


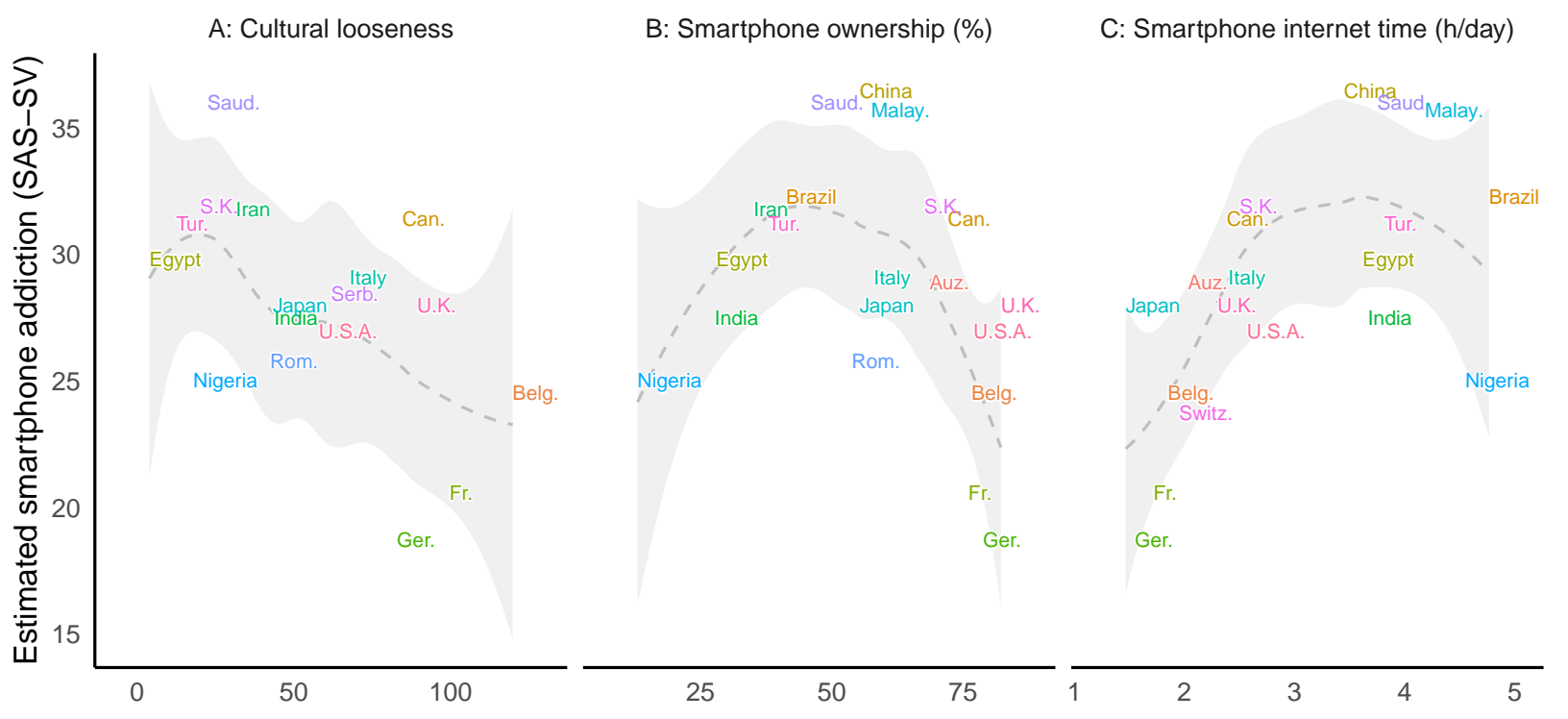

Figure 4: Problematic smartphone use by country-level cultural looseness (Uz, 2015), smartphone ownership (Newzoo, 2018), and smartphone internet time (GlobalWebIndex, 2018). Problematic smartphone use averages show the most recent pooled estimates for each country. Internet time is the average reported time spent on smartphones using the internet (e.g., not during phone calls).

\subsection{Age and gender}

We did not see comparable effects for age and gender. These variables were taken on the sample level rather than the participant level, which reduced statistical power compared to individual difference studies. Younger and female populations generally have higher problematic smartphone use (Andone et al., 2016; Kwon, Kim, et al., 2013; van Deursen et al., 2015).

\section{Discussion}

We conducted, to our knowledge, the largest meta-analysis of problematic smartphone use with comparable measures. We focused on the Smartphone Addiction Scale, the mostcited and perhaps most-used measure of the construct. Results showed that problematic smartphone use increased over time and varied considerably by country. 
The relevance of these results depends on the validity of the construct measured by the SAS. Although the scale predicts clinical judgements (Kwon, Kim, et al., 2013) and better captures shared variance than several other measures (Davidson et al., 2020), its conceptual clarity remains under debate. Davidson and colleagues (2020) argue that some of the items directly measure facets of mental health, which explains their negative correlations with depression and anxiety. Here, increases in problematic smartphone use scores could partly reflect the growing psychological distress across various countries (Twenge et al., 2019, 2021). They further argue that few technology addiction measures follow the best practices in scale development, though the SAS is among the better ones. We agree that these measures should be interpreted with caution, but if the SAS and SAS-SV are currently the de facto standard scales in the field, our global averages may help interpretation until their conceptual clarity is improved (cf. Satchell et al., 2020; Abendroth et al., 2020).

For more precision in our analysis, we focused on the averages of the SAS rather than their clinical cut-off values. Kwon and colleagues (2013), who developed the SAS-SV, proposed initial criteria for determining the risk of smartphone addiction. With an average score of 25, the authors found that cut-off values of 31 for boys and 33 for girls predicted clinical judgements. However, as the authors pointed out, these cut-offs are based on a single sample of South Korean high school students and may be difficult to generalise beyond that region. Eight years later, these provisional cut-offs remain widely used for interpreting scores across the world. Using these cut-offs, the majority of recent samples from China, Saudi Arabia, and Malaysia would be considered at a high risk of smartphone addiction (Figure 2). If phone use is now more integral to daily life than when the scale was first developed, it may be time to update the cut-off values or their clinical interpretations across countries. Doing so would help avoid pathologising social behaviours which are now seen in the majority of teenagers and young adults in some countries (cf. Kardefelt-Winther et al., 2017; Satchell et al., 2020). 


\subsection{Limitations}

Our study had several limitations. Many of the countries had sparse data, making it difficult to assess regional trends. For example, there may be considerable variation between rural and urban settings or between higher- and lower-income regions within the same country. Still, we saw surprisingly little such variation. In the United States, samples from Ohio, Texas, and Massachusetts varied by only 3.35 points on the SAS-SV scale (which ranges from 10 to 60). Cross-country surveys of problematic smartphone use, similar to those regularly undertaken for objective measures (e.g. GlobalWebIndex, 2018; Newzoo, 2021), would allow for more precise regional estimates (Olson, Sandra, Langer, \& Veissière, in progress).

Other limitations of our study relate to generalisation. Excluding clinical samples may have reduced our reported averages, while focusing on a younger population may have increased them (van Deursen et al., 2015). The overall trend over time and the relative differences between the countries may thus be more reliable than our specific effect sizes. Similarly, we are limited in our translation from SAS to SAS-SV scores for our analysis. Although the SAS-SV contains a subset of the SAS items and both scales strongly correlate (Harris, McCredie, et al., 2020), the translation was based on a single American sample which may be difficult to generalise across the world. In any case, avoiding this translation by using only the SAS-SV scores would have changed no hypothesis decisions nor would it have strongly influenced the effect sizes.

\subsection{Future directions}

We focused on scales measuring problematic smartphone use, but as different types of devices converge, researchers may need more sophisticated measures (Abendroth et al., 2020). The boundary has blurred between problematic use of both smartphones and the internet (Chen et al., 2020), with portable devices now accounting for over half of 
all website traffic (Clement, 2021). The lines have also blurred between smartphones, tablets, laptops, and even smart watches; virtual and augmented reality devices may further complicate these distinctions. Forward-thinking measures may help prevent the underestimation of problematic technology use when excluding other devices from standardised scales. For example, our study participants regularly ask whether their small tablets should be considered as smartphones in the SAS; the problematic use itself likely matters more than which particular device it involves. More comprehensive measures may also help clarify how much overlap these constructs have with typical behavioural addictions (Abendroth et al., 2020; Satchell et al., 2020).

Finally, the impact of lockdowns and work-from-home trends during the COVID-19 pandemic remains to be seen. None of the eligible studies in our sample collected data during this period, but other studies have shown a recent increase in technology use (e.g., Cellini et al., 2020). Further, it is unclear whether the same scales are as reliable during social isolation, given that several of the SAS items depend on interaction with others (e.g., "People around me tell me that I use my smartphone too much"; Kwon, Kim, et al., 2013). A follow-up meta-analysis conducted years after the current pandemic would reveal any long-term changes in problematic smartphone use.

\subsection{Conclusion}

Problematic smartphone use increased across the world between 2014 and 2020, and we expect this trend to continue. As organisations track objective measures such as smartphone ownership and screen time, it is also important to assess the subjective aspects and psychological consequences of this proliferation. We hope our results help researchers and policy makers quantify and predict problematic smartphone use across the world. 


\section{Data availability}

The data table is in the Appendix and online (https://osf.io/tq3wv/). The dataset for the translation from SAS to SAS-SV scores (Harris, McCredie, et al., 2020) is also online.

\section{References}

Abendroth, A., Parry, D. A., Roux, D. B. le, \& Gundlach, J. (2020). An analysis of problematic media use and technology use addiction scales - what are they actually assessing? In Lecture notes in computer science (pp. 211-222). Springer International Publishing. https://doi.org/10.1007/978-3-030-45002-1_18

Aker, S., Şahin, M. K., Sezgin, S., \& Oğuz, G. (2017). Psychosocial factors affecting smartphone addiction in university students. Journal of Addictions Nursing, 28(4), 215-219. https:// doi.org/10.1097/jan.0000000000000197

Akodu, A. K., Akinbo, S. R., \& Young, Q. O. (2018). Correlation among smartphone addiction, craniovertebral angle, scapular dyskinesis, and selected anthropometric variables in physiotherapy undergraduates. Journal of Taibah University Medical Sciences, 13(6), 528-534. https://doi.org/10.1016/j.jtumed.2018.09.001

AlAbdulwahab, S. S., Kachanathu, S. J., \& AlMotairi, M. S. (2017). Smartphone use addiction can cause neck disability. Musculoskeletal Care, 15(1), 10-12. https:/ / doi.org/ 10.1002/msc. 1170

Amez, S., Vujić, S., Soffers, P., \& Baert, S. (2020). Yawning while scrolling? Examining gender differences in the association between smartphone use and sleep quality. Journal of Sleep Research. https:/ / doi.org/10.1111/jsr.12971

Andone, I., Błaszkiewicz, K., Eibes, M., Trendafilov, B., Montag, C., \& Markowetz, A. (2016, September). How age and gender affect smartphone usage. Proceedings of the 
2016 ACM International Joint Conference on Pervasive and Ubiquitous Computing: Adjunct. https:/ / doi.org/10.1145/2968219.2971451

Andrade, A. L. M., Kim, D.-J., Caricati, V. V., Martins, G. D. G., Kirihara, I. K., Barbugli, B. C., Enumo, S. R. F., \& Micheli, D. D. (2020). Validity and reliability of the Brazilian version of the smartphone addiction scale-short version for university students and adult population. Estudos de Psicologia (Campinas), 37. https://doi.org/10.1590/1982$0275202037 \mathrm{e} 190117$

Arpaci, I. (2017). Culture and nomophobia: The role of vertical versus horizontal collectivism in predicting nomophobia. Information Development, 35(1), 96-106. https: / / doi.org/10.1177/0266666917730119

Ayandele, O., Popoola, O., Obosi, A., Busari, A., \& others. (2019). Depression, anxiety and smart phone addiction among young people in south west nigeria. Covenant International Journal of Psychology, 4(2).

Ben-Yehuda, L., Greenberg, L., \& Weinstein, A. (2016). Internet addiction by using the smartphone-relationships between internet addiction, frequency of smartphone use and the state of mind of male and female students. Journal of Reward Deficiency Syndrome and Addiction Science, 2(1). https:/ / doi.org/10.17756/jrdsas.2016-024

Bhalerao, M. M., Krishnan, B., Mokal, S. J., \& Latti, R. (2020). An analysis of smartphone addiction among MBBS students. Indian Journal of Clinical Anatomy and Physiology, 7(1), $1-7$.

Bhatt, S., \& Gaur, A. (2019). Psychological risk factors associated with internet and smartphone addiction among students of an indian dental institute. Indian Journal of Public Health, 63(4), 313. https:/ /doi.org/10.4103/ijph.ijph_330_18

Busch, P. A., \& McCarthy, S. (2021). Antecedents and consequences of problematic smartphone use: A systematic literature review of an emerging research area. 114, 106414. https: 


\section{/ / doi.org/10.1016/j.chb.2020.106414}

Can, H. B., \& Tuna, F. (2020). Relation between endurance of deep cervical flexor muscles and physical activity level, perceived stress, sleep quality, and smartphone addiction. CRANIO, 1-9. https:/ / doi.org/10.1080/08869634.2020.1724457

Celikkalp, U., Bilgic, S., Temel, M., \& Varol, G. (2020). The smartphone addiction levels and the association with communication skills in nursing and medical school students. Journal of Nursing Research, 28(3), e93. https:/ / doi.org/10.1097/jnr.0000000000000370

Cellini, N., Canale, N., Mioni, G., \& Costa, S. (2020). Changes in sleep pattern, sense of time and digital media use during COVID-19 lockdown in Italy. Journal of Sleep Research, 29(4). https://doi.org/10.1111/jsr.13074

Cerit, B., Bilgin, N. Çıtak, \& Ak, B. (2018). Relationship between smartphone addiction of nursing department students and their communication skills. Contemporary Nurse, 54(4-5), 532-542. https:/ / doi.org/10.1080/10376178.2018.1448291

Chen, I.-H., Pakpour, A. H., Leung, H., Potenza, M. N., Su, J.-A., Lin, C.-Y., \& Griffiths, M. D. (2020). Comparing generalized and specific problematic smartphone/internet use: Longitudinal relationships between smartphone application-based addiction and social media addiction and psychological distress. 9(2), 410-419. https://doi.org/10.1556/2006.2020.00 023

Choi, S.-W., Kim, D.-J., Choi, J.-S., Ahn, H., Choi, E.-J., Song, W.-Y., Kim, S., \& Youn, H. (2015). Comparison of risk and protective factors associated with smartphone addiction and internet addiction. Journal of Behavioral Addictions, 4(4), 308-314. https: / / doi.org/10.1556/2006.4.2015.043

Choi, S.-W., Mok, J. Y., Kim, D.-J., Choi, J.-S., Lee, J.-W., Ahn, H.-J., Choi, E.-J., \& Song, W.-Y. (2014). Latent class analysis on internet and smartphone addiction in college students. Neuropsychiatric Disease and Treatment, 817. https:/ /doi.org/10.2147/ndt.s59293 
Clement, J. (2021). Percentage of mobile device website traffic worldwide from 1st quarter 2015 to 1st quarter 2021. In Statistica. https://www.statista.com/statistics/277125/s hare-of-website-traffic-coming-from-mobile-devices /

Coban, D. (2019). Investigation of the relationship between smartphone addiction and overweight on university students. Annals of Medical Research, 26(10), 2172. https: / / doi.org/10.5455/annalsmedres.2019.08.446

Cocoradă, E., Maican, C. I., Cazan, A.-M., \& Maican, M. A. (2018). Assessing the smartphone addiction risk and its associations with personality traits among adolescents. Children and Youth Services Review, 93, 345-354. https://doi.org/10.1016/j.childyouth.2 018.08.006

Çevik, C., Ciğerci, Y., K1lıç, \& Uyar, S. (2020). Relationship between smartphone addiction and meaning and purpose of life in students of health sciences. Perspectives in Psychiatric Care. https:/ / doi.org/10.1111/ppc.12485

Çizmeci, E. (2017). No time for reading, addicted to scrolling: The relationship between smartphone addiction and reading attitudes of Turkish youth. Intermedia International E-Journal, 4(7), 290-302. https:/ / doi.org/10.21645/intermedia.2017.37

Darcin, A. E., Kose, S., Noyan, C. O., Nurmedov, S., Yılmaz, O., \& Dilbaz, N. (2016). Smartphone addiction and its relationship with social anxiety and loneliness. Behaviour E Information Technology, 35(7), 520-525. https:/ / doi.org/10.1080/0144929x.2016.1158 319

Davidson, B., Shaw, H., \& Ellis, D. (2020). Fuzzy constructs in assessment: The overlap between mental health and technology "use". PsyArXiv. https://doi.org/10.17605/O SF.IO/84J6H

Deloitte. (2018). 2018 global mobile consumer survey: US edition. https:/ / www2.deloitte.co m/content/dam/Deloitte/us/Documents/technology-media-telecommunications 
/us-tmt-global-mobile-consumer-survey-exec-summary-2018.pdf

Deloitte. (2019). Deloitte's 2019 global mobile consumer survey. https: / / www2.deloitte.co $\mathrm{m} /$ us/en/insights/industry/telecommunications/global-mobile-consumer-survey2019.html

Demirci, K., Akgönül, M., \& Akpinar, A. (2015). Relationship of smartphone use severity with sleep quality, depression, and anxiety in university students. Journal of Behavioral Addictions, 4(2), 85-92. https:/ / doi.org/10.1556/2006.4.2015.010

Demirci, K., Orhan, H., Demirdas, A., Akpinar, A., \& Sert, H. (2014). Validity and reliability of the turkish version of the smartphone addiction scale in a younger population. Klinik Psikofarmakoloji Bülteni-Bulletin of Clinical Psychopharmacology, 24(3), 226-234. https:/ / doi.org/10.5455/bcp.20140710040824

Dey, M., Studer, J., Schaub, M. P., Gmel, G., Ebert, D. D., Lee, J. Y.-C., \& Haug, S. (2019). Problematic smartphone use in young Swiss men: Its association with problematic substance use and risk factors derived from the pathway model. Journal of Behavioral Addictions, 8(2), 326-334. https:/ / doi.org/10.1556/2006.8.2019.17

Dharmadhikari, S. P., Harshe, S. D., \& Bhide, P. P. (2019). Prevalence and correlates of excessive smartphone use among medical students: A cross-sectional study. Indian Journal of Psychological Medicine, 41(6), 549-555. https:/ / doi.org/10.4103/ijpsym.ijpsy m_75_19

Dikeç, G., \& Kebapçı, A. (2018). Smartphone addiction level among a group of university students. Bağımlılık Dergisi, 19(1), 1-9.

Elhai, J. D., Dvorak, R. D., Levine, J. C., \& Hall, B. J. (2017). Problematic smartphone use: A conceptual overview and systematic review of relations with anxiety and depression psychopathology. Journal of Affective Disorders, 207, 251-259. https://doi.org/10.1016/ j.jad.2016.08.030 
Elhai, J. D., Gallinari, E. F., Rozgonjuk, D., \& Yang, H. (2020). Depression, anxiety and fear of missing out as correlates of social, non-social and problematic smartphone use. Addictive Behaviors, 105, 106335. https://doi.org/10.1016/j.addbeh.2020.106335

Elhai, J. D., Levine, J. C., O'Brien, K. D., \& Armour, C. (2018). Distress tolerance and mindfulness mediate relations between depression and anxiety sensitivity with problematic smartphone use. Computers in Human Behavior, 84, 477-484. https: / / doi.org/10.1016/j.chb.2018.03.026

Elhai, J. D., Rozgonjuk, D., Alghraibeh, A. M., Levine, J. C., Alafnan, A. A., Aldraiweesh, A. A., Aljomaa, S. S., \& Hall, B. J. (2020). Excessive reassurance seeking mediates relations between rumination and problematic smartphone use. Bulletin of the Menninger Clinic, 84(2), 137-155. https://doi.org/10.1521/bumc_2020_84_07

Elhai, J. D., Tiamiyu, M. F., Weeks, J. W., Levine, J. C., Picard, K. J., \& Hall, B. J. (2018a). Depression and emotion regulation predict objective smartphone use measured over one week. Personality and Individual Differences, 133, 21-28. https://doi.org/10.1016/j. paid.2017.04.051

Elhai, J. D., Tiamiyu, M., \& Weeks, J. (2018b). Depression and social anxiety in relation to problematic smartphone use. Internet Research, 28(2), 315-332. https://doi.org/10.110 8/intr-01-2017-0019

Elhai, J. D., Vasquez, J. K., Lustgarten, S. D., Levine, J. C., \& Hall, B. J. (2018). Proneness to boredom mediates relationships between problematic smartphone use with depression and anxiety severity. Social Science Computer Review, 36(6), 707-720. https:/ / doi.org/ $10.1177 / 0894439317741087$

Elhai, J. D., Yang, H., Dempsey, A. E., \& Montag, C. (2020). Rumination and negative smartphone use expectancies are associated with greater levels of problematic smartphone use: A latent class analysis. Psychiatry Research, 285, 112845. https: 


\section{/ /doi.org/10.1016/j.psychres.2020.112845}

Elhai, J. D., Yang, H., Fang, J., Bai, X., \& Hall, B. J. (2020). Depression and anxiety symptoms are related to problematic smartphone use severity in Chinese young adults: Fear of missing out as a mediator. Addictive Behaviors, 101, 105962. https: / / doi.org/10.1016/j.addbeh.2019.04.020

Elhai, J. D., Yang, H., Rozgonjuk, D., \& Montag, C. (2020). Using machine learning to model problematic smartphone use severity: The significant role of fear of missing out. Addictive Behaviors, 103, 106261. https://doi.org/10.1016/j.addbeh.2019.106261

Elkholy, H., Elhabiby, M., \& Ibrahim, I. (2020). Rates of alexithymia and its association with smartphone addiction among a sample of university students in Egypt. Frontiers in Psychiatry, 11. https://doi.org/10.3389/fpsyt.2020.00304

Ellis, D. A., Davidson, B. I., Shaw, H., \& Geyer, K. (2019). Do smartphone usage scales predict behavior? International Journal of Human-Computer Studies, 130, 86-92. https: / / doi.org/10.1016/j.ijhcs.2019.05.004

Enwereuzor, I. K., Ugwu, L. I., \& Ugwu, D. I. (2016). Role of smartphone addiction in gambling passion and schoolwork engagement: A dualistic model of passion approach. Asian Journal of Gambling Issues and Public Health, 6(1). https:/ / doi.org/10.1186/s40405016-0018-8

Geng, Y., Gu, J., Wang, J., \& Zhang, R. (2021). Smartphone addiction and depression, anxiety: The role of bedtime procrastination and self-control. Journal of Affective Disorders, 293, 415-421. https:/ / doi.org/10.1016/j.jad.2021.06.062

GlobalWebIndex. (2018). Devices. GlobalWebIndex's Flagship Report on Device Ownership and Usage.

Gutiérrez, J. D.-S., Fonseca, F. R. de, \& Rubio, G. (2016). Cell-phone addiction: A review. Frontiers in Psychiatry, 7. https://doi.org/10.3389/fpsyt.2016.00175 
Harris, B., McCredie, M., \& Fields, S. (2020). Examining the psychometric properties of the Smartphone Addiction Scale and its short version for use with emerging adults in the U.S. Computers in Human Behavior Reports, 1, 100011. https:/ / doi.org/10.1016/j.ch br.2020.100011

Harris, B., Regan, T., Schueler, J., \& Fields, S. A. (2020). Problematic mobile phone and smartphone use scales: A systematic review. Frontiers in Psychology, 11. https: / / doi.org/10.3389/fpsyg.2020.00672

Haug, S., Castro, R. P., Kwon, M., Filler, A., Kowatsch, T., \& Schaub, M. P. (2015). Smartphone use and smartphone addiction among young people in switzerland. Journal of Behavioral Addictions, 4(4), 299-307. https:/ / doi.org/10.1556/2006.4.2015.037

Hughes, N., \& Burke, J. (2018). Sleeping with the frenemy: How restricting "bedroom use" of smartphones impacts happiness and wellbeing. Computers in Human Behavior, $85,236-244$.

Hunt, M. G., Marx, R., Lipson, C., \& Young, J. (2018). No more FOMO: Limiting social media decreases loneliness and depression. Journal of Social and Clinical Psychology, 37(10), 751-768. https:/ / doi.org/10.1521/jscp.2018.37.10.751

Hunter, J. E., \& Schmidt, F. L. (2004). Methods of meta-analysis: Correcting error and bias in research findings. Sage.

İnal, E. E., Demırc1, K., Çetıntürk, A., Akgönül, M., \& Savaş, S. (2015). Effects of smartphone overuse on hand function, pinch strength, and the median nerve. Muscle E Nerve, 52(2), 183-188. https:/ / doi.org/10.1002/mus.24695

Ithnain, N., Ghazali, S. E., Jaafar, N., \& others. (2018). Relationship between smartphone addiction with anxiety and depression among undergraduate students in Malaysia. International Journal of Health Sciences and Research, 8(1), 163-171. 
Kardefelt-Winther, D., Heeren, A., Schimmenti, A., Rooij, A. van, Maurage, P., Carras, M., Edman, J., Blaszczynski, A., Khazaal, Y., \& Billieux, J. (2017). How can we conceptualize behavioural addiction without pathologizing common behaviours? 112(10), 1709-1715. https: / / doi.org/10.1111/add.13763

Karki, S., Singh, J. P., Paudel, G., Khatiwada, S., \& Timilsina, S. (2020). How addicted are newly admitted undergraduate medical students to smartphones?: A cross-sectional study from Chitwan Medical College, Nepal. BMC Psychiatry, 20(1). https:/ /doi.org/ 10.1186/s12888-020-02507-1

Karkusha, R. N., Mosaad, D. M., \& Kader, B. S. A. (2019). Effect of smartphone addiction on neck function among undergraduate physical therapist students. The Egyptian Journal of Hospital Medicine, 76(4), 4034-4038. https:/ / doi.org/10.21608/ ejhm.2019.421 31

Konan, N., Durmuş, E., Türkoğlu, D., \& Bakır, A. A. (2018). How is smartphone addiction related to interaction anxiety of prospective teachers? Education Sciences, 8(4), 186. https://doi.org/10.3390/educsci8040186

Kurugodiyavar, M. D., R., S. H., Godbole, M., \& Nekar, M. S. (2017). Impact of smartphone use on quality of sleep among medical students. International Journal of Community Medicine and Public Health, 5(1), 101. https:/ / doi.org/10.18203/2394-6040.ijcmph20175 604

Kwon, M., Kim, D.-J., Cho, H., \& Yang, S. (2013). The smartphone addiction scale: Development and validation of a short version for adolescents. PLOS ONE, 8(12), e83558. https:/ / doi.org/10.1371/journal.pone.0083558

Kwon, M., Lee, J.-Y., Won, W.-Y., Park, J.-W., Min, J.-A., Hahn, C., Gu, X., Choi, J.-H., \& Kim, D.-J. (2013). Development and validation of a smartphone addiction scale (SAS). PLOS ONE, 8(2), e56936. https://doi.org/10.1371/journal.pone.0056936 
Lachmann, B., Duke, Sariyska, R., \& Montag, C. (2019). Who's addicted to the smartphone and/or the internet? Psychology of Popular Media Culture, 8(3), 182-189. https:/ / doi.or g/10.1037/ppm0000172

Lachmann, B., Sindermann, C., Sariyska, R. Y., Luo, R., Melchers, M. C., Becker, B., Cooper, A. J., \& Montag, C. (2018). The role of empathy and life satisfaction in internet and smartphone use disorder. Frontiers in Psychology, 9. https://doi.org/10.3389/fpsy g.2018.00398

Lajeunesse, M. J. (2015). Facilitating systematic reviews, data extraction and meta-analysis with the metagear package for R. Methods in Ecology and Evolution, 7(3), 323-330. https://doi.org/10.1111/2041-210x.12472

Liu, C., \& Ma, J. (2018). Social support through online social networking sites and addiction among college students: The mediating roles of fear of missing out and problematic smartphone use. Current Psychology. https://doi.org/10.1007/s12144-0180075-5

Long, J., Wang, P., Liu, S., \& Lei, L. (2019). Materialism and adolescent problematic smartphone use: The mediating role of fear of missing out and the moderating role of narcissism. Current Psychology. https:/ / doi.org/10.1007/s12144-019-00526-0

Lopez-Fernandez, O., Kuss, D. J., Romo, L., Morvan, Y., Kern, L., Graziani, P., Rousseau, A., Rumpf, H.-J., Bischof, A., Gässler, A.-K., \& others. (2017). Self-reported dependence on mobile phones in young adults: A European cross-cultural empirical survey. Journal of Behavioral Addictions, 6(2), 168-177.

Lukoff, K., Yu, C., Kientz, J., \& Hiniker, A. (2018). What makes smartphone use meaningful or meaningless? Proceedings of the ACM on Interactive, Mobile, Wearable and Ubiquitous Technologies, 2(1), 1-26. https://doi.org/10.1145/3191754 
Minkov, M. (2018). A revision of Hofstede's model of national culture: Old evidence and new data from 56 countries. Cross Cultural \& Strategic Management, 25(2), 231-256. https:/ / doi.org/10.1108/ccsm-03-2017-0033

Moher, D., Liberati, A., Tetzlaff, J., \& Altman, D. G. (2009). Preferred reporting items for systematic reviews and meta-analyses: The PRISMA statement. Annals of Internal Medicine, 151(4), 264-269.

Mokhtarinia, H., Rafinia, M., Shahbazi, A., Ardakani, M. R. K., Harouni, G. R. G., \& Gabel, C. P. (2020). The cross-cultural adaptation of the smartphone addiction scale to persian. Iranian Rehabilitation Journal, 91-98. https:/ / doi.org/10.32598/irj.18.1.919.1

Montag, C., Zhao, Z., Sindermann, C., Xu, L., Fu, M., Li, J., Zheng, X., Li, K., Kendrick, K. M., Dai, J., \& Becker, B. (2018). Internet communication disorder and the structure of the human brain: Initial insights on WeChat addiction. Scientific Reports, 8(1). https://doi.org/10.1038/s41598-018-19904-y

Newzoo. (2018). Global mobile market report.

Newzoo. (2019). Global mobile market report.

Newzoo. (2021). Global mobile market report. https://newzoo.com/insights/trendreports/newzoo-global-mobile-market-report-2021-free-version/

Nowreen, N., \& Ahad, F. (2018). Effect of smartphone usage on quality of sleep in medical students. National Journal of Physiology, Pharmacy and Pharmacology, 8(9), 1366. https:/ / doi.org/10.5455/njppp.2018.8.0620009062018

O'Dea, S. (2021). Number of smartphone users worldwide from 2016 to 2021. Statista. https: / / www.statista.com/statistics/330695/number-of-smartphone-usersworldwide/ 
Olson, J. A., Sandra, D. A., Chmoulevitch, D., Raz, A., \& Veissière, S. P. L. (2021). A nudge-based intervention to reduce problematic smartphone use. PsyArXiv. https: / / doi.org/10.31234/osf.io/tjynk

Olson, J. A., Stendel, M., \& Veissière, S. (2020). Hypnotised by your phone? Smartphone addiction correlates with hypnotisability. Frontiers in Psychiatry, 11. https://doi.org/ 10.3389/fpsyt.2020.00578

Ozer, O. (2020). Smartphone addiction and fear of missing out: Does smartphone use matter for students' academic performance? Journal of Computer and Education Research, 344-355. https:// doi.org/10.18009/jcer.696481

Panova, T., \& Carbonell, X. (2018). Is smartphone addiction really an addiction? Journal of Behavioral Addictions, 7(2), 252-259.

Pasquale, C. D., Sciacca, F., \& Hichy, Z. (2017). Italian validation of Smartphone Addiction Scale Short Version for adolescents and young adults (SAS-SV). Psychology, 08(10), 1513-1518. https://doi.org/10.4236/psych.2017.810100

Pew Research Center. (2019). Mobile fact sheet. Pew Research Center: Internet, Science $\mathcal{E}$ Tech. https://www.pewresearch.org/internet/fact-sheet/mobile/

Przybylski, A. K. (2019). Digital screen time and pediatric sleep: Evidence from a preregistered cohort study. The Journal of Pediatrics, 205, 218-223.e1. https://doi.org/ 10.1016/j.jpeds.2018.09.054

Randjelovic, P., Stojiljkovic, N., Radulovic, N., Stojanovic, N., \& Ilic, I. (2020). Problematic smartphone use, screen time and chronotype correlations in university students. European Addiction Research, 1-8. https://doi.org/10.1159/000506738

Rao, S., Sethuraman, A. R., \& Thatkar, P. (2019). Comparative study of smartphone addiction among arts and medical college students of Port Blair. Community Med, 10(6), 375-379. 
Rémond, J.-J., \& Romo, L. (2018). Analysis of gambling in the media related to screens: Immersion as a predictor of excessive use? International Journal of Environmental Research and Public Health, 15(1), 58. https:/ / doi.org/10.3390/ijerph15010058

Rideout, V. J., \& Robb, M. B. (2019). The common sense census: Media use by tweens and teens.

Rozgonjuk, D., Levine, J. C., Hall, B. J., \& Elhai, J. D. (2018). The association between problematic smartphone use, depression and anxiety symptom severity, and objectively measured smartphone use over one week. Computers in Human Behavior, 87, 10-17. https://doi.org/10.1016/j.chb.2018.05.019

Sanal, Y., \& Ozer, Ö. (2017). Smartphone addiction and the use of social media among university students. Mediterranean Journal of Humanities, 7(2), 367-377. https: / / doi.or g/10.13114/mjh.2017.370

Satchell, L. P., Fido, D., Harper, C. A., Shaw, H., Davidson, B., Ellis, D. A., Hart, C. M., Jalil, R., Bartoli, A. J., Kaye, L. K., Lancaster, G. L. J., \& Pavetich, M. (2020). Development of an offline-friend addiction questionnaire (o-FAQ): Are most people really social addicts? 53(3), 1097-1106. https:/ / doi.org/10.3758/s13428-020-01462-9

Satici, B., \& Engin Deniz, M. (2020). Modeling emotion regulation and subjective happiness: Smartphone addiction as a mediator. ADDICTA: The Turkish Journal on Addictions. https:/ / doi.org/10.5152/addicta.2020.20035

Selçuk, K. T., \& Ayhan, D. (2019). The relationship between smartphone addiction risk and sleep duration and psychosocial comorbidities in health professional candidates. Perspectives in Psychiatric Care. https://doi.org/10.1111/ppc.12465

Sethuraman, A. R., Rao, S., Charlette, L., Thatkar, P. V., \& Vincent, V. (2018). Smartphone addiction among medical college students in the Andaman and Nicobar Islands. International Journal of Community Medicine and Public Health, 5(10), 4273. https: / / doi.org/10.18203/2394-6040.ijcmph20183867 
Shah, P. P., \& Sheth, M. S. (2018). Correlation of smartphone use addiction with text neck syndrome and SMS thumb in physiotherapy students. International Journal of Community Medicine and Public Health, 5(6), 2512. https://doi.org/10.18203/23946040.ijcmph20182187

Sohn, S. Y., Krasnoff, L., Rees, P., Kalk, N. J., \& Carter, B. (2021). The association between smartphone addiction and sleep: A UK cross-sectional study of young adults. Frontiers in Psychiatry, 12. https://doi.org/10.3389/fpsyt.2021.629407

Sohn, S. Y., Rees, P., Wildridge, B., Kalk, N. J., \& Carter, B. (2019). Prevalence of problematic smartphone usage and associated mental health outcomes amongst children and young people: A systematic review, meta-analysis and GRADE of the evidence. BMC Psychiatry, 19(1). https://doi.org/10.1186/s12888-019-2350-x

Soni, R., Upadhyay, R., \& Jain, M. (2017). Prevalence of smart phone addiction, sleep quality and associated behaviour problems in adolescents. International Journal of Research in Medical Sciences, 5(2), 515. https:/ / doi.org/10.18203/2320-6012.ijrms201701 42

Soyer, F. (2019). Smartphone addiction and leisure constraints: College students. International Journal of Psychology and Educational Studies, 6(2), 26-34. https://doi.org/10.172 20/ijpes.2019.02.003

Sönmez, M., Kısacık, Ö. G., \& Eraydın, C. (2020). Correlation between smartphone addiction and loneliness levels in nursing students. Perspectives in Psychiatric Care. https://doi.org/10.1111/ppc.12527

Tan, P. S., \& Arshat, Z. (2019). Parental attachment, smartphone addiction and stress among undergraduate students. International Journal of Education, Psychology and Counseling, 4(32), 149-163. https:/ / doi.org/10.35631/ijepc.4320015 
Tateno, M., Kim, D.-J., Teo, A. R., Skokauskas, N., Guerrero, A. P. S., \& Kato, T. A. (2019). Smartphone addiction in japanese college students: Usefulness of the japanese version of the smartphone addiction scale as a screening tool for a new form of internet addiction. Psychiatry Investigation, 16(2), 115-120. https://doi.org/10.30773/pi.2018.1 2.25 .2

Tateno, M., Teo, A. R., Ukai, W., Kanazawa, J., Katsuki, R., Kubo, H., \& Kato, T. A. (2019). Internet addiction, smartphone addiction, and hikikomori trait in Japanese young adult: Social isolation and social network. Frontiers in Psychiatry, 10. https: / / doi.org/10.3389/fpsyt.2019.00455

Turgeman, L., Hefner, I., Bazon, M., Yehoshua, O., \& Weinstein, A. (2020). Studies on the relationship between social anxiety and excessive smartphone use and on the effects of abstinence and sensation seeking on excessive smartphone use. International Journal of Environmental Research and Public Health, 17(4), 1262. https://doi.org/10.3390/ijerph 17041262

Twenge, J. M., Blake, A. B., Haidt, J., \& Campbell, W. K. (2020). Commentary: Screens, teens, and psychological well-being: Evidence from three time-use-diary studies. Frontiers in Psychology, 11. https:/ / doi.org/10.3389/fpsyg.2020.00181

Twenge, J. M., Cooper, A. B., Joiner, T. E., Duffy, M. E., \& Binau, S. G. (2019). Age, period, and cohort trends in mood disorder indicators and suicide-related outcomes in a nationally representative dataset, 20052017. Journal of Abnormal Psychology, 128(3), 185-199. https:// doi.org/10.1037/abn0000410

Twenge, J. M., Haidt, J., Blake, A. B., McAllister, C., Lemon, H., \& Roy, A. L. (2021). Worldwide increases in adolescent loneliness. Journal of Adolescence. https://doi.org/ 10.1016/j.adolescence.2021.06.006 
Uz, I. (2015). The index of cultural tightness and looseness among 68 countries. Journal of Cross-Cultural Psychology, 46(3), 319-335. https://doi.org/https://doi.org/10.1177/00 22022114563611

van Deursen, A. J., Bolle, C. L., Hegner, S. M., \& Kommers, P. A. (2015). Modeling habitual and addictive smartphone behavior: The role of smartphone usage types, emotional intelligence, social stress, self-regulation, age, and gender. Computers in Human Behavior, 45, 411-420.

Veissière, S. P. L., \& Stendel, M. (2018). Hypernatural monitoring: A social rehearsal account of smartphone addiction. Frontiers in Psychology, 9, 141.

Venkatesh, E., Jemal, M. Y. A., \& Samani, A. S. A. (2017). Smart phone usage and addiction among dental students in Saudi Arabia: A cross sectional study. International Journal of Adolescent Medicine and Health, 31(1). https:/ / doi.org/10.1515/ijamh-2016-0133

Volungis, A. M., Kalpidou, M., Popores, C., \& Joyce, M. (2019). Smartphone addiction and its relationship with indices of social-emotional distress and personality. International Journal of Mental Health and Addiction. https:/ / doi.org/10.1007/s11469-019-00119-9

Wang, P., Lei, L., Wang, X., Nie, J., Chu, X., \& Jin, S. (2018). The exacerbating role of perceived social support and the "buffering" role of depression in the relation between sensation seeking and adolescent smartphone addiction. Personality and Individual Differences, 130, 129-134. https:/ / doi.org/10.1016/j.paid.2018.04.009

Wang, P., Nie, J., Wang, X., Wang, Y., Zhao, F., Xie, X., Lei, L., \& Ouyang, M. (2018). How are smartphones associated with adolescent materialism? Journal of Health Psychology, 135910531880106. https:/ / doi.org/10.1177/1359105318801069

Wang, P., Wang, X., Nie, J., Zeng, P., Liu, K., Wang, J., Guo, J., \& Lei, L. (2019). Envy and problematic smartphone use: The mediating role of FOMO and the moderating role of student-student relationship. Personality and Individual Differences, 146, 136-142. 
https://doi.org/10.1016/j.paid.2019.04.013

Wang, P., Zhao, M., Wang, X., Xie, X., Wang, Y., \& Lei, L. (2017). Peer relationship and adolescent smartphone addiction: The mediating role of self-esteem and the moderating role of the need to belong. Journal of Behavioral Addictions, 6(4), 708-717. https: / / doi.org/10.1556/2006.6.2017.079

Wilmer, H. H., Sherman, L. E., \& Chein, J. M. (2017). Smartphones and cognition: A review of research exploring the links between mobile technology habits and cognitive functioning. Frontiers in Psychology, 8, 1-16. https:/ / doi.org/10.3389/fpsyg.2017.00605

Winskel, H., Kim, T.-H., Kardash, L., \& Belic, I. (2019). Smartphone use and study behavior: A Korean and Australian comparison. Heliyon, 5(7), e02158. https://doi.or g/10.1016/j.heliyon.2019.e02158

Wolniewicz, C. A., Rozgonjuk, D., \& Elhai, J. D. (2019). Boredom proneness and fear of missing out mediate relations between depression and anxiety with problematic smartphone use. Human Behavior and Emerging Technologies, 2(1), 61-70. https:/ / doi.or g/10.1002/hbe2.159

Wright, K., Golder, S., \& Rodriguez-Lopez, R. (2014). Citation searching: A systematic review case study of multiple risk behaviour interventions. BMC Medical Research Methodology, 14(1). https:/ / doi.org/10.1186/1471-2288-14-73

Yalcinkaya, G., Sengul Salik, Y., \& Buker, N. (2020). The effect of calling duration on cervical joint repositioning error angle and discomfort in university students. Work, 65(3), 473-482. https://doi.org/10.3233/WOR-203102

Yang, Z., Asbury, K., \& Griffiths, M. D. (2019). An exploration of problematic smartphone use among Chinese university students: Associations with academic anxiety, academic procrastination, self-regulation and subjective wellbeing. International Journal of Mental Health and Addiction, 17(3), 596-614. https://doi.org/10.1007/s11469-018-9961-1 
Yayan, E. H., Düken, M. E., Dağ, Y. S., \& Ulutaş, A. (2018). Examination of the relationship between nursing student's internet and smartphone addictions. Journal of Human Sciences, 15(2), 1161. https:// doi.org/10.14687/jhs.v15i2.5247

Yuchang, J., Cuicui, S., Junxiu, A., \& Junyi, L. (2017). Attachment styles and smartphone addiction in Chinese college students: The mediating roles of dysfunctional attitudes and self-esteem. International Journal of Mental Health and Addiction, 15(5), 1122-1134. https: / / doi.org/10.1007/s11469-017-9772-9

Zencirci, S. A., Aygar, H., Göktaş, S., Önsüz, M. F., Alaiye, M., \& Metintaş, S. (2018). Evaluation of smartphone addiction and related factors among university students. International Journal of Research in Medical Sciences, 6(7), 2210. https://doi.org/10.18203 /2320-6012.ijrms20182805 


\section{A Appendix}

Figure A1 shows the translation between the two problematic smartphone use measures, Figure A2 shows world maps for each measure, and Table A1 summarises all of the articles used.

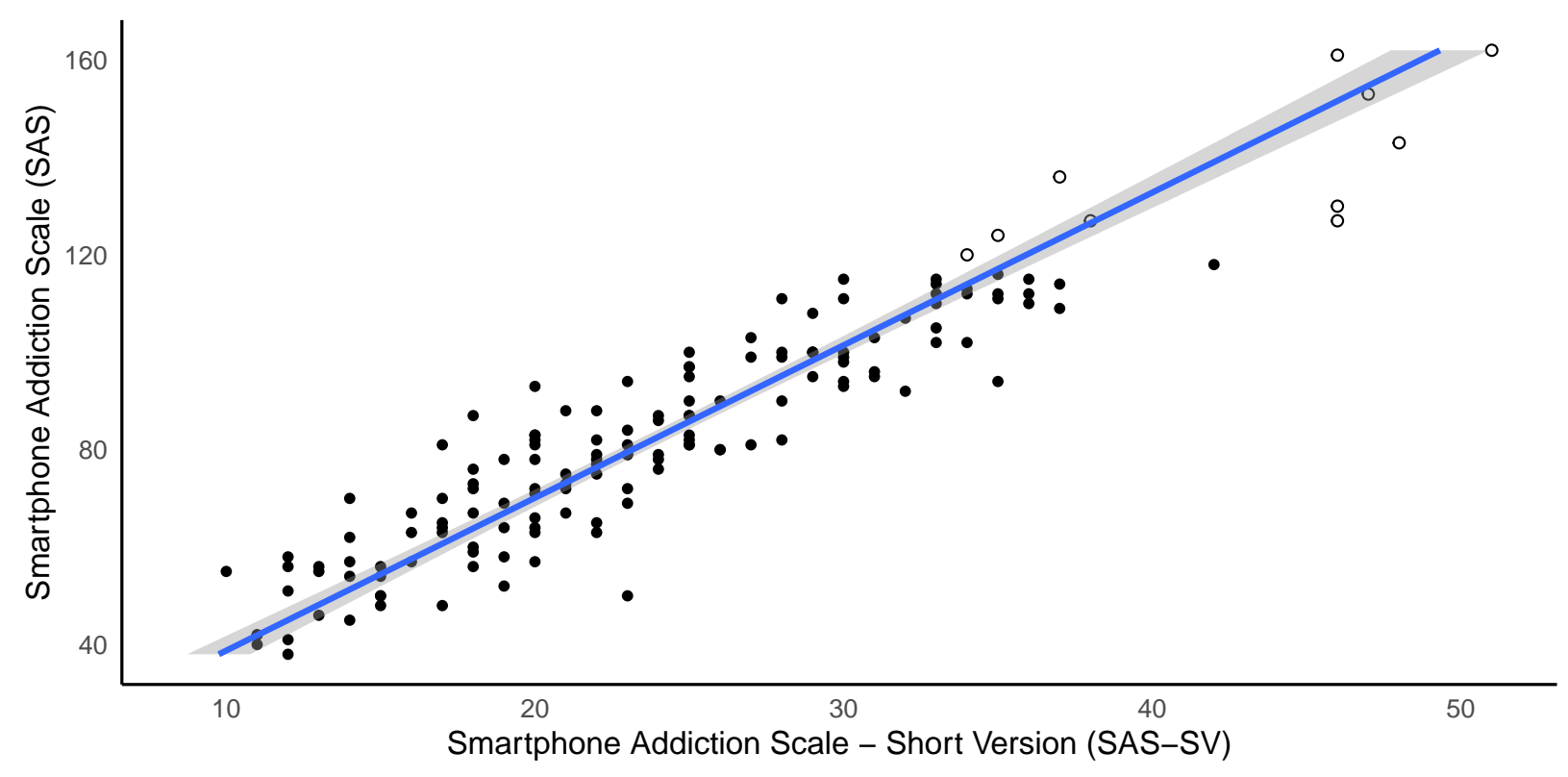

Figure A1: Smartphone Addiction Scale (SAS) and its short version (SAS-SV), based on raw data from Harris and colleagues (2020). The scales showed a strong linear relationship, allowing us to translate SAS scores to estimated SAS-SV scores. Filled dots show data within range of observed SAS averages. 


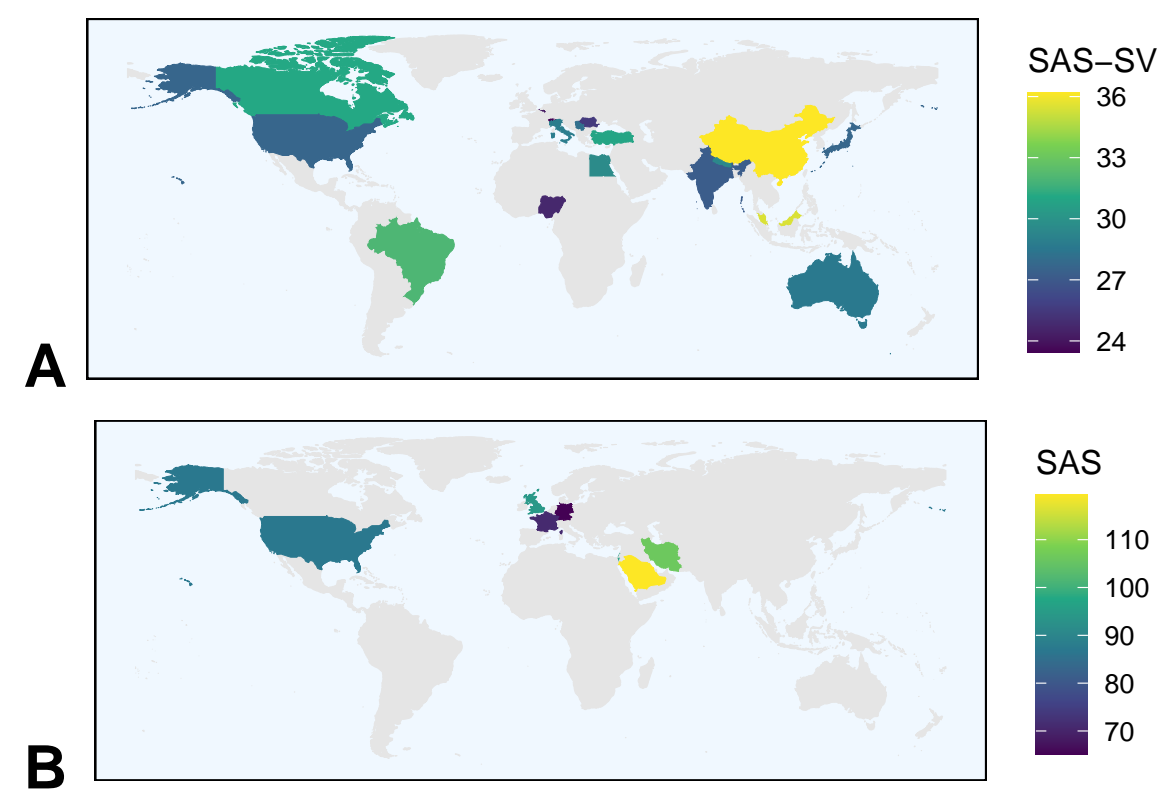

Figure A2: Pooled average of most recent year of eligible problematic smartphone use scores (SAS-SV in A and SAS in B) by country. 
Table A1: Studies and subsamples used in meta-analysis. Values show means \pm standard deviations, with range in parentheses. Tildes $(\sim)$ show averages estimated by the midpoint of the range.

\begin{tabular}{|c|c|c|c|c|c|c|}
\hline Measure & Country & Citation & $N$ & $\%$ female & Age & SAS or SAS-SV \\
\hline \multirow[t]{52}{*}{ SAS-SV } & Australia & (Winskel et al., 2019) & 270 & 78 & $21.26 \pm 2.55(18-26)$ & $28.61 \pm 9.32$ \\
\hline & Belgium & (Amez et al., 2020) & 1889 & 53 & 18.78 & 24.24 \\
\hline & Brazil & (Andrade et al., 2020) & 387 & - & $22.10 \pm 5.07$ & $32.00 \pm 8.60$ \\
\hline & Canada & (Olson et al., 2020) & 475 & 70 & $21.07 \pm 3.12(18-35)$ & $31.11 \pm 8.96(10-56)$ \\
\hline & China & $\begin{array}{l}\text { (Elhai, Yang, Fang, et al., } \\
\text { 2020) }\end{array}$ & 1034 & 65 & $19.34 \pm 1.61$ & $34.92 \pm 11.39$ \\
\hline & China & $\begin{array}{l}\text { (Elhai, Yang, Rozgonjuk, } \\
\text { et al., 2020) }\end{array}$ & 1097 & 82 & $19.38 \pm 1.18$ & $37.36 \pm 9.54$ \\
\hline & China & (Long et al., 2019) & 677 & 41 & $16.79 \pm 0.72(15-19)$ & $34.10 \pm 9.10$ \\
\hline & China & (Wang et al., 2019) & 724 & 43 & $16.79 \pm 0.91$ & $34.20 \pm 9.10$ \\
\hline & China & (Yang et al., 2019) & 475 & 44 & $19.77 \pm 1.11(16-27)$ & $36.70 \pm 7.55(10-60)$ \\
\hline & China & (Lachmann et al., 2018) & 612 & 26 & $21.55 \pm 2.44(18-32)$ & $34.20 \pm 9.30$ \\
\hline & China & (Liu \& Ma, 2018) & 465 & 69 & $18.83 \pm 1.08(16-24)$ & $31.13 \pm 9.38$ \\
\hline & China & (Montag et al., 2018) & 61 & 34 & $22.34 \pm 2.29$ & $34.43 \pm 9.01(14-52)$ \\
\hline & China & (Wang, Lei, et al., 2018) & 655 & 45 & $16.80 \pm 0.74(15-19)$ & $34.70 \pm 8.70$ \\
\hline & China & (Wang, Nie, et al., 2018) & 748 & 56 & $16.80 \pm 0.73(15-19)$ & $34.10 \pm 9.10$ \\
\hline & China & (Wang et al., 2017) & 768 & 56 & $16.81 \pm 0.73(15-19)$ & $34.00 \pm 6.90$ \\
\hline & China & (Yuchang et al., 2017) & 297 & 45 & $20.24 \pm 1.08(17-24)$ & $23.74 \pm 7.49$ \\
\hline & Egypt & (Elkholy et al., 2020) & 200 & 58 & $21.23 \pm 1.99(17-27)$ & $29.54 \pm 10.92$ \\
\hline & Egypt & (Karkusha et al., 2019) & 100 & - & $21.08 \pm 1.86(19-24)$ & $33.97 \pm 7.47$ \\
\hline & India & (Bhalerao et al., 2020) & 178 & 56 & $19.28 \pm 0.93$ & $27.20 \pm 9.65$ \\
\hline & India & $\begin{array}{l}\text { (Dharmadhikari et al., } \\
\text { 2019) }\end{array}$ & 195 & 51 & $20.23 \pm 1.63(17-27)$ & $31.59 \pm 9.89(10-57)$ \\
\hline & India & (Nowreen \& Ahad, 2018) & 212 & - & $19.76(17-22)$ & 27.16 \\
\hline & Italy & (Pasquale et al., 2017) & 633 & 55 & 18.00 & $28.82 \pm 8.90$ \\
\hline & Japan & (Tateno, Teo, et al., 2019) & 487 & 73 & $19.60 \pm 1.50(18-28)$ & $29.60 \pm 8.80(10-59)$ \\
\hline & Japan & (Tateno, Kim, et al., 2019) & 573 & 69 & $19.30 \pm 1.30$ & $26.10 \pm 10.00$ \\
\hline & Malaysia & (Tan \& Arshat, 2019) & 400 & 67 & $22.98 \pm 1.55$ & 35.43 \\
\hline & Nepal & (Karki et al., 2020) & 250 & 61 & $19.70 \pm 1.68(18-29)$ & $29.41 \pm 8.94$ \\
\hline & Nigeria & (Ayandele et al., 2019) & 500 & 52 & $21.95 \pm 2.88(16-32)$ & $24.73 \pm 8.77$ \\
\hline & Nigeria & (Akodu et al., 2018) & 77 & 43 & $21.94 \pm 2.40$ & $31.39 \pm 7.82$ \\
\hline & Romania & (Cocoradă et al., 2018) & 717 & 65 & 19.80 & $25.52 \pm 9.57$ \\
\hline & Saudi Arabia & (Venkatesh et al., 2017) & 189 & 47 & 23.29 & 36.29 \\
\hline & Serbia & (Randjelovic et al., 2020) & 77 & - & $\sim 21(20-22)$ & $28.16 \pm 1.69(10-53)$ \\
\hline & South Korea & (Winskel et al., 2019) & 119 & 50 & $20.64 \pm 1.71(18-26)$ & $31.62 \pm 9.69$ \\
\hline & Switzerland & (Haug et al., 2015) & 1519 & 52 & $18.20 \pm 3.60(15-21)$ & $23.45 \pm 8.34$ \\
\hline & Turkey & (Can \& Tuna, 2020) & 104 & 50 & $20.15 \pm 1.32(18-24)$ & $29.87 \pm 10.82(11-58)$ \\
\hline & Turkey & (Celikkalp et al., 2020) & 502 & 71 & $21.20 \pm 1.86$ & $31.89 \pm 9.90$ \\
\hline & Turkey & (Çevik et al., 2020) & 677 & 74 & $20.20 \pm 2.12$ & $30.62 \pm 10.42$ \\
\hline & Turkey & (Ozer, 2020) & 139 & 42 & $19.88 \pm 1.59(18-26)$ & $29.51 \pm 10.15$ \\
\hline & Turkey & $\begin{array}{l}\text { (Satici \& Engin Deniz, } \\
\text { 2020) }\end{array}$ & 320 & 52 & $21.06 \pm 1.76(18-26)$ & $30.46 \pm 10.63$ \\
\hline & Turkey & (Sönmez et al., 2020) & 682 & 74 & $20.76 \pm 1.72$ & $31.40 \pm 10.17$ \\
\hline & Turkey & (Yalcinkaya et al., 2020) & 63 & 62 & $22.84 \pm 1.86(18-25)$ & $28.47 \pm 10.43$ \\
\hline & Turkey & (Coban, 2019) & 325 & 57 & $22.38 \pm 3.15$ & $32.32 \pm 9.80$ \\
\hline & Turkey & (Selçuk \& Ayhan, 2019) & 408 & 81 & $20.13 \pm 2.43(18-32)$ & $29.41 \pm 10.08(10-60)$ \\
\hline & Turkey & (Soyer, 2019) & 1298 & 48 & $20.61 \pm 1.67(18-24)$ & $31.19 \pm 10.36$ \\
\hline & Turkey & (Konan et al., 2018) & 330 & 64 & $\sim 22(20-24)$ & $28.22 \pm 11.41(10-60)$ \\
\hline & Turkey & (Zencirci et al., 2018) & 1492 & - & $20.40 \pm 1.70(18-24)$ & $26.00(10-60)$ \\
\hline & Turkey & (Aker et al., 2017) & 494 & 76 & $20.22 \pm 1.11$ & $28.91 \pm 11.34$ \\
\hline & Turkey & (Çizmeci, 2017) & 344 & 70 & $\sim 24(18-29)$ & $29.11 \pm 8.23$ \\
\hline & Turkey & (Sanal \& Ozer, 2017) & 157 & 46 & $18.94 \pm 0.96$ & $26.83 \pm 12.31$ \\
\hline & United States & $\begin{array}{l}\text { (Elhai, Gallinari, et al., } \\
\text { 2020) }\end{array}$ & 316 & 67 & $19.21 \pm 1.74(18-25)$ & $27.41 \pm 9.41$ \\
\hline & United States & $\begin{array}{l}\text { (Elhai, Yang, Dempsey, et } \\
\text { al., 2020) }\end{array}$ & 286 & 63 & $19.72 \pm 2.60(18-25)$ & $27.88 \pm 9.41$ \\
\hline & United States & $\begin{array}{l}\text { (Elhai, Tiamiyu, et al., } \\
\text { 2018b) }\end{array}$ & 296 & 57 & $20.00 \pm 3.02$ & $27.08 \pm 10.15$ \\
\hline & United States & (Elhai, Tiamiyu, et al., & 68 & 65 & $19.75 \pm 2.03(18-25)$ & $25.82 \pm 10.57$ \\
\hline
\end{tabular}




\begin{tabular}{|c|c|c|c|c|c|c|}
\hline Measure & Country & Citation & $N$ & $\%$ female & Age & SAS or SAS-SV \\
\hline & United States & $\begin{array}{l}\text { (Elhai, Levine, et al., } \\
\text { 2018) }\end{array}$ & 261 & 77 & $19.73 \pm 3.52$ & $26.31 \pm 10.35$ \\
\hline \multirow[t]{30}{*}{ SAS } & France & (Rémond \& Romo, 2018) & 432 & 51 & $21.94 \pm 5.51$ & $71.01 \pm 28.71$ \\
\hline & Germany & (Lachmann et al., 2019) & 612 & 71 & $23.55 \pm 5.92$ & $65.22 \pm 24.72$ \\
\hline & India & (Bhatt \& Gaur, 2019) & 320 & 79 & 21.00 & 108.00 \\
\hline & India & (Rao et al., 2019) & 341 & 72 & $18.92 \pm 1.65$ & $100.64 \pm 28.16$ \\
\hline & India & (Sethuraman et al., 2018) & 192 & 67 & $18.15 \pm 0.74(17-20)$ & $101.26 \pm 26.30$ \\
\hline & India & (Shah \& Sheth, 2018) & 100 & 76 & $21.80 \pm 1.29(20-25)$ & $102.49 \pm 22.15$ \\
\hline & India & $\begin{array}{l}\text { (Kurugodiyavar et al., } \\
\text { 2017) }\end{array}$ & 240 & 41 & $19.90(18-24)$ & $102.93 \pm 22.13(33-166)$ \\
\hline & India & (Soni et al., 2017) & 511 & 42 & $16.50 \pm 2.58$ & $79.10 \pm 12.44$ \\
\hline & Iran & (Mokhtarinia et al., 2020) & 100 & 58 & $24.46 \pm 4.14$ & $106.19 \pm 29.25$ \\
\hline & Israel & (Turgeman et al., 2020) & 140 & 48 & $26.33 \pm 3.38(22-35)$ & $96.22 \pm 33.56$ \\
\hline & Israel & (Turgeman et al., 2020) & 60 & 73 & $23.83 \pm 2.22(19-30)$ & $95.70 \pm 25.89(38-196)$ \\
\hline & Israel & (Ben-Yehuda et al., 2016) & 40 & 50 & $24.10 \pm 1.87(21-29)$ & $85.22 \pm 22.56(41-140.67)$ \\
\hline & Malaysia & (Ithnain et al., 2018) & 369 & - & $19.32 \pm 0.98(19-30)$ & $102.52 \pm 21.07$ \\
\hline & Saudi Arabia & $\begin{array}{l}\text { (AlAbdulwahab et al., } \\
\text { 2017) }\end{array}$ & 78 & 50 & $21.30 \pm 1.70$ & $119.40 \pm 20.70$ \\
\hline & South Korea & (Choi et al., 2015) & 448 & 60 & $20.89 \pm 3.09$ & $68.46 \pm 24.95(33-198)$ \\
\hline & South Korea & (Choi et al., 2014) & 448 & 60 & $20.94 \pm 2.86$ & $68.70 \pm 23.84$ \\
\hline & Turkey & (Cerit et al., 2018) & 214 & 80 & $20.39 \pm 1.45(18-26)$ & $86.43 \pm 29.66$ \\
\hline & Turkey & (Dikeç \& Kebapçı, 2018) & 265 & 56 & $21.04 \pm 2.63(18-24)$ & $84.88 \pm 22.96$ \\
\hline & Turkey & (Yayan et al., 2018) & 788 & 58 & $20.80 \pm 2.67$ & $90.58 \pm 29.44(33-167)$ \\
\hline & Turkey & (Darcin et al., 2016) & 367 & 62 & $19.50 \pm 1.15$ & 88.38 \\
\hline & Turkey & (Demirci et al., 2015) & 248 & 64 & $20.50 \pm 2.45$ & $75.68 \pm 22.46$ \\
\hline & Turkey & (İnal et al., 2015) & 66 & 76 & 20.97 & $84.86 \pm 13.07$ \\
\hline & Turkey & (Demirci et al., 2014) & 301 & 56 & $20.59 \pm 2.35$ & 75.76 \\
\hline & $\begin{array}{l}\text { United } \\
\text { Kingdom }\end{array}$ & (Ellis et al., 2019) & 238 & 52 & $31.88 \pm 11.19$ & $94.20 \pm 30.17$ \\
\hline & United States & $\begin{array}{l}\text { (Elhai, Rozgonjuk, et al., } \\
\text { 2020) }\end{array}$ & 295 & 72 & $19.70 \pm 3.97$ & $88.37 \pm 22.95$ \\
\hline & United States & $\begin{array}{l}\text { (Harris, McCredie, et al., } \\
2020 \text { ) }\end{array}$ & 150 & 67 & $19.20 \pm 1.20(18-24)$ & $84.29 \pm 25.03$ \\
\hline & United States & (Volungis et al., 2019) & 150 & 83 & 19.28 & $93.23 \pm 19.00(38-148)$ \\
\hline & United States & (Wolniewicz et al., 2019) & 297 & 72 & $19.70 \pm 3.96$ & $91.52 \pm 23.95(33-157)$ \\
\hline & United States & $\begin{array}{l}\text { (Elhai, Vasquez, et al., } \\
\text { 2018) }\end{array}$ & 298 & 77 & $19.45 \pm 2.17$ & $93.47 \pm 25.30(34-164.28)$ \\
\hline & United States & (Rozgonjuk et al., 2018) & 101 & 76 & $19.53 \pm 4.31$ & $94.00 \pm 24.08(41-146)$ \\
\hline
\end{tabular}

